\title{
A licenciatura como ato performativo: reflexões sobre a formação universitária do professor de Língua Portuguesa
}

\author{
The undergraduate degree as a performative act: reflections \\ on academic education of Portuguese language teacher
}

\section{Marcos Bispo dos Santos}

Professor Adjunto do Curso de Letras - Língua Portuguesa e Literaturas, Departamento de Educação - Campus II - Universidade do Estado da Bahia - Bahia, Brasil

\section{RESUMO}

Na política educacional brasileira, o diploma de licenciatura constitui uma titulação acadêmica de nível superior que não apenas significa a conclusão de um ciclo formal de estudos, mas, sobretudo, um ato performativo que transforma, automaticamente, o graduado em um profissional habilitado para atuar como professor de determinada disciplina na educação básica. Neste artigo, problematizou-se se a concessão do diploma de licenciado em Letras significa que todas as condições básicas necessárias para a formação profissionalizante inicial do professor de língua portuguesa foram atendidas. O quadro teórico conceitual que fundamentou a análise e discussão das práticas de formação foi apresentado através da exposição crítica das principais perspectivas de formação docente que influenciam o debate no âmbito acadêmico. A avaliação do caráter performativo da licenciatura se deu por meio da triangulação de três diferentes eixos: a legislação educacional, os objetivos do ensino na educação básica e a formação universitária do professor. Concluiu-se que a performatividade da licenciatura em Letras não é acompanhada de uma profissionalização efetiva.

Palavras-chave: Formação docente. Licenciatura em Letras. Profissionalização do professor. 


\section{ABSTRACT}

In the Brazilian educational policy, the bachelor's degree is an academic degree that not only means the completion of a formal course of study, but above all a performative act that transforms automatically the graduate into a qualified professional to act as a teacher of certain discipline in basic education. In this paper, we discuss if a bachelor's degree in Letters means that all the basic conditions necessary for the initial vocational training of the Portuguese language teacher were met. The conceptual theoretical framework that justified the analysis and discussion of training practices was presented by critical exposition of the main perspectives of teacher education that influence the debate in the academic field. The evaluation of the performative character of the bachelor's degree was through triangulation of three different areas: educational legislation, educational objectives in basic education and university education. Our analysis shows that the performativity of the bachelor's degree in Letters is not accompanied by an effective professionalization.

Keywords: Teacher training. Bachelor's Degree in Letters. Teacher professionalization.

\section{Introdução}

A noção de ato performativo, usada neste artigo para caracterizar a licenciatura, foi tomada de empréstimo da teoria dos atos de fala desenvolvida por John Austin, no contexto da filosofia analítica, e que mais tarde contribuiu para a consolidação de uma importante perspectiva da pragmática linguística. $\mathrm{O}$ ato performativo designa a ação linguística que, ao ser enunciada, não apenas diz, mas simultaneamente faz, desde que sejam atendidas certas condições, o que pode ser resumido na fórmula "dizer é fazer". Desse modo, ao estabelecer a analogia entre o ato performativo na teoria de Austin e a licenciatura pretendo, por um lado, assinalar a performatividade da licenciatura que, ao ser concedida a um estudante, confere-lhe o status de profissional, e, por outro, questionar se, de fato, a concessão do diploma de licenciado significa que todas as condições básicas necessárias para a formação profissionalizante inicial do professor de língua portuguesa foram atendidas. 
Uma definição bem geral do que seja a profissionalização do professor é apresentada por Altet (2001:25), que a concebe como " $a$ passagem do oficio artesanal, em que se aplicam técnicas e regras, a uma profissão, em que cada um constrói suas estratégias apoiando-se em conhecimentos racionais e desenvolvendo sua especialização de ação na própria situação profissional, assim como sua autonomia". Contudo, historicamente, diferentes modelos de formação profissional foram sendo forjados, principalmente no âmbito das instituições socialmente responsáveis pela profissionalização docente. Tais modelos têm influenciado não apenas as crenças de professores e formadores a respeito do que seja a profissão docente, como também as políticas educacionais, explicitadas através de legislações unificadoras de caráter nacional. Assim, demonstrar o caráter performativo da licenciatura impõe investigá-la por meio da triangulação de três diferentes eixos: a legislação educacional, os objetivos da educação básica e a formação universitária do professor.

Na primeira parte do texto, farei uma apresentação dos principais modelos de formação de professores. Essa opção se justifica pelo fato de que a parte da legislação educacional que dispõe sobre a formação docente enfatiza a necessidade de desenvolvimento de competências profissionais. Desse modo, a exposição preliminar das perspectivas de formação permitirá uma melhor abordagem da legislação, uma vez que cada perspectiva se fundamenta em determinados pressupostos teórico-metodológicos que nos permitirão situar os aspectos legais no quadro geral dos modelos formativos.

Na segunda parte, apresentarei as bases legais que tratam especificamente da formação do professor de língua portuguesa. A legislação estabelece pressupostos de formação segundo os quais o trabalho desenvolvido na universidade deve proporcionar aos estudantes a aquisição ou construção das competências básicas para o exercício da profissão na educação básica. Como esses documentos situam a formação do professor no contexto dos eixos de triangulação acima referidos, será através da análise do funcionamento desses eixos que o caráter performativo da licenciatura em Letras será avaliado. 


\section{Perspectivas de formação profissional de professores}

A educação, como um processo sociopolítico de extrema complexidade e espaço de intensos debates e conflitos, representa um centro catalisador de práticas culturais e sociodiscursivas que se renovam e se atualizam à medida que essas práticas vão renovando e atualizando suas referências. Um dado importante nesse processo de transformações, que refletem na educação muitas contingências do dinamismo social, é que os aspectos inovadores não se superpõem absolutamente aos vigentes de modo a constituir novos paradigmas hegemônicos no campo empírico, ainda que isso ocorra no âmbito estritamente teórico. Em geral, a inovação coexiste, em sentido prático, com concepções total ou parcialmente deslegitimadas por estudos acadêmicos. Nesse sentido, a educação se caracteriza como um conjunto de discursos e práticas heteróclitos, muitas vezes contraditórios, que apresentam enormes desafios a todos os profissionais que atuam no campo educacional, com especial destaque para o professor. Diante desse contexto, qualquer reflexão sobre a profissionalização do professor, nos cursos de licenciatura, deve passar, obrigatoriamente, por uma discussão acerca dos modelos de formação docente.

Existem diferentes modelos de formação docente, que variam em virtude das complexas relações entre a sociedade e os fatores teóricos e políticos que envolvem a educação. O mais antigo deles é o professor magister (ALTET, 2001), um modelo de mestre da antiguidade que possuía notório saber, adquirido sem a necessidade de uma formação específica, mas legitimado por uma tradição. A profissionalização propriamente dita do professor tem lugar na história da educação a partir da exigência de certificação específica, emitida por instituições legalmente incumbidas de oferecer cursos de formação docente. Tal procedimento funciona como um mecanismo de interdição, proibindo os que não cumprem à risca os processos fixados pelos dispositivos institucionalizados de exercer o ofício. A seguir, serão apresentadas as perspectivas de formação profissional de professores mais representativas no cenário acadêmico atual, de acordo com a classificação proposta por Pérez Gómez (1998). 


\section{A perspectiva acadêmica}

Essa perspectiva é a que ainda predomina nos cursos de formação de professores no Brasil e se caracteriza por conceber o docente como um especialista que acumula conhecimentos tipicamente acadêmicos produzidos por meio da investigação científica, seja no campo das disciplinas puramente teóricas ou de propostas de transferência dos conhecimentos teóricos ao ensino por meio de ciências aplicadas. Nesse modelo, a formação de professores se dá sem o devido cuidado com o conhecimento didático e pedagógico, principalmente quando se trata daqueles que não estão relacionados diretamente com as disciplinas de natureza eminentemente teórica ou com seu modo de apresentação e transmissão.

A perspectiva acadêmica assinala o primeiro momento da formação de professores, após a obrigatoriedade do curso superior como condição para o exercício do magistério. Contudo, como a exigência legal da formação universitária não se deu em consonância com a adequação da universidade a essa nova demanda, o que se verificou foi o alinhamento do processo formativo à lógica do funcionamento institucional da universidade, fortemente influenciada pela racionalidade científica. Nesse cenário, a formação de professores não persegue objetivos voltados para o desenvolvimento de competências profissionais, mas concebe o futuro professor como um especialista nas diferentes disciplinas. Desse modo, prioriza a dimensão científica dos saberes conceituais, processuais e condicionais ou atitudinais, em detrimento da dimensão profissional relativa a esses saberes. Ou seja, a relação com o saber no processo formativo se dá sob a égide do apriorismo do conhecimento científico, produzido, em grande medida, à revelia do contexto real de exercício da profissão.

A cientifização da pedagogia e da didática (PLAISANCE; VERGNAUD, 2003) subordinou essas práticas à lógica da fragmentação e especialização que caracteriza a ciência moderna. A complexidade inerente à prática educativa atomizou-se em objetos particulares de estudo reivindicados por pesquisadores especialistas, a exemplo da avaliação, da escrita, da leitura, da sociologia e da psicologia aplicadas à educação. Os currículos dos cursos de formação de professores buscam minimizar os efeitos dessa fragmentação por meio da criação 
de disciplinas cujas ementas preveem a articulação de objetos de diferentes disciplinas científicas. Contudo, a desvinculação entre conhecimento acadêmico e saberes experienciais converte as disciplinas curriculares em espaços nos quais se discute a teoria da prática, esta, em geral, idealizada.

No âmbito das licenciaturas, o fosso entre a teoria e a prática é ainda mais profundo. Nos cursos de Letras, por exemplo, a especialização coloca de um lado os professores responsáveis pelos saberes didáticos e pedagógicos e do outro, os responsáveis pelos saberes referentes às teorias linguísticas e literárias. Dessa forma, separa-se o estudo dos processos de ensino-aprendizagem de seu objeto, dado que os formadores especialistas não conseguem relacioná-los. Logo, os professores das áreas de linguística e literatura acabam, do modo geral, não se comprometendo com a transformação do conhecimento teórico/ técnico em conhecimento/conteúdo didático para a educação básica. Nesse sentido, não é exagerado afirmar que, na perspectiva acadêmica, a formação de professores é um objetivo que se verifica mais no plano da estrutura curricular e menos no nível empírico ao longo de todo o curso de graduação. Consequentemente, o estágio obrigatório costuma ser o momento em que o futuro profissional percebe com maior clareza os limites e as contradições de uma formação universitária que não o capacita efetivamente para o exercício competente da profissão.

Apesar dos limites amplamente conhecidos do modelo acadêmico de formação de professores, ele não apenas se revela muito atual como também demonstra grande poder de adaptação diante dos demais modelos, nos quais a imprescindibilidade da relação teoria-prática é bastante enfatizada. Isso se deve, sobretudo, ao prestígio da ciência moderna no contexto universitário e à primazia que este concede à teoria, geralmente entendida como anterior à prática ou como condição de possibilidade dela. Assim, os pressupostos epistemológicos de qualquer outro modelo de formação docente podem ser assimilados e abordados apenas do ponto de vista teórico no âmbito da perspectiva acadêmica. Ademais, a prioridade da teoria faz com que a (in)experiência profissional dos formadores na educação básica seja vista como um componente irrelevante nos processos de seleção e contratação de pessoal, bastando apenas o domínio teórico considerado adequado para alguém se tornar professor universitário. Com isso, verifica-se uma 
contradição: as políticas de formação de professores admitem que um professor universitário possa desconhecer o contexto profissional em sua complexidade e, mesmo assim, atuar como formador de profissionais que exercerão seu ofício nesse mesmo contexto.

Diante desses problemas, Perrenoud (2002) avalia que a exigência da formação universitária para o professor sem a devida adequação desta aos objetivos da profissionalização docente faz com que apenas virtualmente a universidade seja um contexto privilegiado para formar educadores. Tal adequação incluiria:

[...] orientar com clareza a formação dos professores para uma prática reflexiva, valorizar os saberes advindos da experiência e da ação dos profissionais e desenvolver uma forte articulação teoria-prática e uma verdadeira profissionalização. Essas transformações questionam o status epistemológico das ciências da educação e a vocação das unidades que o exigem. (PERRENOUD, 2002, p. 90).

O questionamento da racionalidade científica como paradigma norteador da formação profissional de professores não significa uma recusa à pesquisa ou à cientificidade no processo formativo, em favor de práticas meramente intuitivas e desprovidas de embasamento teórico. O que se propõe é a substituição de uma epistemologia fundada no apriorismo da teoria por uma epistemologia da prática (SCHÖN, 2000), em que a teoria seja produzida por meio do estudo sistemático da prática profissional. Com base nesse postulado, a teoria e a prática da profissionalização do professor se tornaram objetos de estudo de vários pesquisadores. Apenas para citar alguns exemplos, Tardif(2011) apresenta considerações decorrentes de pesquisas que investigaram o papel dos saberes docentes na formação profissional; Paquay, Perrenoud, Altet e Charlier (2001) discutem as competências profissionais dos professores e quais as estratégias para alcançá-las; Perrenoud (2002) aprofunda o debate sobre a noção de prática reflexiva e seu papel na construção de uma razão pedagógica; Sacristán e Pérez Gómez (1998) problematizam a necessidade da compreensão da complexidade inerente ao ensino como condição necessária para transformá-lo; Altet (2000) apresenta uma metodologia para a análise das práticas dos professores e das situações pedagógicas; Hartman (2015) apresenta os elementos de uma didática geral para o professor reflexivo; Paquay, Nieuwenhoven 
e Wouters (2012) analisam a avaliação como ferramenta de desenvolvimento profissional de educadores; Weinstein e Novodvorsky (2015) propõem orientações para a gestão da sala de aula na educação básica, a partir de pesquisas sobre a prática.

É importante ressaltar que os trabalhos citados se situam no campo da pesquisa pedagógica ou da didática geral. É preciso desenvolver pesquisas no âmbito da epistemologia da prática voltados para as disciplinas específicas, dentre elas, a língua portuguesa.

\section{A perspectiva técnica}

A perspectiva técnica se propõe a dar ao ensino um status e um rigor ausentes na prática tradicional, ao concebê-lo como uma ciência aplicada. O professor, por sua vez, é caracterizado como um técnico que domina a aplicação do conhecimento científico produzido por outros e transformado em regras de atuação.

Tal modelo de racionalidade técnica é uma epistemologia da prática derivada da filosofia positivista, construída nas próprias fundações das universidades e dedicada à pesquisa (SCHÖN, 2000). Por meio dela, a atividade profissional é identificada com uma prática instrumental, dirigida à solução de problemas por meio da aplicação rigorosa de teorias e técnicas científicas.

Inspirada em modelos de formação próprios da medicina e da engenharia, e tendo em vista a busca por status acadêmico, o currículo normativo de formação docente no âmbito da racionalidade técnica opera mediante uma hierarquia de conhecimentos. Em primeiro lugar, aparecem as ciências básicas, que, por apresentarem os fundamentos propriamente científicos da formação, ocupam o maior espaço na estrutura curricular. Em segundo, as ciências aplicadas, que, como a própria designação sugere, aplicam os conhecimentos científicos a determinados contextos. Constituem exemplos de ciências aplicadas a sociologia e a psicologia quando orientadas especificamente para o estudo da educação. No quadro da didática geral, são designadas como sociologia da educação e psicologia da educação. No campo da didática do ensino de língua portuguesa, diversos pesquisadores de disciplinas das áreas de linguística e literatura têm se empenhado em apresentar 
possibilidades de aplicação de conhecimentos científicos que produzem ao ensino de língua portuguesa na educação básica. Em terceiro, tem espaço o trabalho com as habilidades técnicas e as práticas cotidianas, normalmente reservado aos períodos de estágio, que costumam ocorrer após o tempo destinado ao estudo das ciências básicas e aplicadas. Tal hierarquização dos saberes pressupõe que as etapas preliminares ao desenvolvimento de habilidades técnicas de caráter prático fornecem todas as bases conceituais e teórico-metodológicas necessárias para orientar o exercício profissional.

Uma das críticas mais relevantes a essa concepção de racionalidade prática foi feita por Schön (2000). A constatação de que a prática profissional é eivada de situações problemáticas e zonas de indefinição que escapam ao domínio das teorias científicas, levou-o a concluir que aquilo que os aspirantes a profissionais mais precisam aprender as escolas profissionais parecem menos capazes de ensinar. Como solução para esse dilema, propõe uma inversão na ordem predominante na estrutura organizacional dos cursos de formação profissional: "em lugar de começar perguntando de que forma podemos fazer melhor uso do conhecimento oriundo da pesquisa, deveríamos partir de um exame cuidadoso do talento artístico, ou seja, da competência através da qual os profissionais realmente dão conta de zonas indeterminadas da prática..." (SCHÖN, 2000, p 22).

Tal proposta não nega importância à ciência aplicada ou à técnica baseada em pesquisa, ainda que reconheça suas limitações quanto ao potencial de compreensão do talento artístico próprio de profissionais competentes. Na avaliação de Schön, a construção de uma epistemologia da prática, uma teoria da ação profissional, precisa considerar a relação entre três diferentes tipos de arte: uma arte da sistematização de problemas, uma arte da implementação e uma arte da improvisação todas necessárias para medir o uso, na prática, da ciência aplicada e da técnica. Assim, tal epistemologia da prática postula que a profissionalização deve se dar a partir de um ensino prático reflexivo, voltado para ajudar os estudantes a adquirir os tipos de talento artístico essenciais para a competência em zonas indeterminadas da prática. 


\section{A perspectiva prática}

A perspectiva prática apoia-se no pressuposto de que o ensino é uma atividade complexa, que se desenvolve em cenários singulares, claramente determinados pelo contexto, com resultados em grande parte imprevisíveis e carregados de conflitos de valor, que requerem opções éticas e políticas (GÓMEZ, 1998). Nesse modelo, a formação do professor baseia-se na aprendizagem da prática, para a prática e por meio da prática. A importante evolução histórica por que passou essa perspectiva permite distingui-la em duas correntes distintas: o enfoque tradicional, apoiado quase que exclusivamente na experiência prática, e o enfoque que enfatiza a prática reflexiva.

No enfoque tradicional, concebe-se o ensino como uma prática artesanal e o conhecimento do ofício é transmitido de geração em geração por meio de processos miméticos, imitativos, de práticos experientes. Trata-se de um conhecimento tácito, escassamente verbalizado e sem organização teórica explícita e sistemática. O aprendiz o adquire por imersão, num longo processo de indução e socialização profissional.

No Brasil, esse foi modelo de formação do professor de português até a década de 1980, quando as teorias linguísticas e literárias substituíram a tradição filológica como referências para a organização curricular dos cursos de Letras. Essa mudança de paradigma representou, adicionalmente, a passagem da perspectiva tradicional de formação de professores para a acadêmica e, mais recentemente, a técnica.

O enfoque reflexivo surge, inicialmente, como uma reação ao ensino tradicional baseado em métodos educacionais transmissivos, com hipervalorização do registro mnemônico como indicador de aprendizagem e fundado na rigidez hierárquica entre os atores do processo educativo: o professor como detentor do conhecimento e responsável por sua transmissão aos alunos, sujeitos passivos no processo educacional. As críticas de Dewey (1977) a esse modelo representaram as mais significativas contribuições a favor do ensino como atividade prática, com destaque para seu famigerado princípio pedagógico de aprender mediante a ação e sua não menos importante proposta de formar um professor reflexivo. Para Dewey, a reflexão é um processo em que se integram atitudes e capacidades nos métodos de investigação, tendo 
por base o pressuposto de que a experiência é o fundamento para o conhecimento da realidade.

No Brasil, a influência das ideias de Dewey nas políticas educacionais se mostrou de maneira mais significativa na reestruturação curricular da educação básica, que rompeu com a perspectiva clássica e elitista, amplamente criticada e combatida pelo movimento da Escola Nova. A primeira Lei de Diretrizes e Bases da Educação Nacional (LDBN 4.024/61) é resultado dos intensos debates que se travaram no país em favor de uma política educacional mais adequada às especificidades da realidade brasileira. Entretanto, como a pesquisa ainda não era um ponto forte das universidades brasileiras (ROMANELLI, 2003), a letra da lei não se consubstanciou em práticas de formação docente que pudessem pôr em prática os princípios defendidos pelos defensores do escolanovismo que militaram pela reformulação curricular e, consequentemente, suplantar o enfoque tradicional de ensino e formação de professores.

O academicismo e a racionalidade técnica representaram os alvos seguintes das críticas do enfoque reflexivo, que, em suas diferentes perspectivas, apresenta em comum o objetivo de superar a relação hierárquica, linear e mecânica entre o conhecimento científico-técnico e a prática de ensino. Mais do que isso, partem do reconhecimento da necessidade de analisar o que realmente fazem os professores quando enfrentam problemas complexos ligados à prática de ensino, como requisito indispensável para se compreender como utilizam o conhecimento científico e sua capacidade intelectual, como enfrentam situações incertas e desconhecidas, como elaboram e modificam rotinas, experimentam hipóteses de trabalho, utilizam técnicas, instrumentos e materiais conhecidos, como recriam estratégias e como inventam procedimentos, tarefas e recursos.

Embora atribua relevo aos conhecimentos técnicos e científicos na formação profissional, o enfoque reflexivo denuncia a ilusão cientificista que propõe transformar os professores em pesquisadores amadores. Perrenoud (2002, p. 101) estabelece, de maneira precisa, o alcance das contribuições de uma formação para a pesquisa, na profissionalização docente: 
[...] a prática de ensino não é e nunca será uma prática de pesquisa, pois é exercida em condições nas quais a decisão é urgente e o valor do saber é medido mais pela sua eficácia pragmática do que pela coerência teórica ou pelas regras do método, as quais permitiram sua elaboração controlada. $\mathrm{O}$ que os professores mais podem aprender, em contato com a pesquisa em educação, provém do olhar, das questões que ela suscita, e não tanto dos métodos e das técnicas. É próprio da pesquisa subverter a percepção, revelar o oculto, suspeitar o inconfessável, estabelecer ligações que não saltam aos olhos, reconstruir as coerências sistêmicas sob a aparente desordem. A principal contribuição prática no âmbito da educação é sua teoria ou, mais modestamente, o conjunto dos paradigmas de interpretativos que as ciências humanas propõem acerca dos fatos didáticos e educativos.

Ao contrário do que se evidencia na perspectiva técnica, em que o professor é visto como um tecnólogo habilitado para a aplicação de conhecimentos e técnicas científicas entendidas como suficientes para o desempenho profissional, a demarcação proposta por Perrenoud postula que a principal regulação da prática docente provém da reflexão do próprio profissional, desde que ele seja capaz de propor questões, de aprender a partir da experiência, de inovar, observar, ajustar progressivamente sua ação às reações previsíveis dos outros. Nesse sentido, as teorias das ciências humanas não podem pretender substituir a prática reflexiva do professor em situação. No melhor dos casos, podem fecundá-la, incentivá-la, propor algumas ferramentas, alguns conceitos e hipóteses que reforcem seu poder e legitimidade (SCHÖN, 2000).

Pérez Gómez (1998) também adverte que o conhecimento acadêmico, teórico, científico ou técnico só pode ser considerado instrumento dos processos de reflexão quando for integrado significativamente, não em parcelas isoladas da memória semântica, mas nos esquemas de pensamento mais genéricos que o indivíduo ativa ao interpretar a realidade concreta em que vive e sobre a qual atua, e quando organiza sua própria experiência. Isso equivale a dizer que não se trata de um conhecimento puro ou fragmentado que obedece à lógica da pesquisa científica, mas de um conhecimento contaminado pelas contingências que rodeiam e impregnam a própria experiência vital.

A reflexão, portanto, não é meramente um processo psicológico que pode ser estudado apenas do ponto de vista formal, desvinculado 
do conteúdo do contexto e das interações. A reflexão implica a imersão consciente do sujeito no mundo de sua experiência, um mundo carregado de conotações, valores, trocas simbólicas, correspondências afetivas, interesses sociais e cenários políticos. Ao contrário de outras formas de conhecimento, a reflexão supõe um sistemático esforço de análise, como a necessidade de elaborar uma proposta totalizadora, que possibilita uma leitura situacional em toda a sua complexidade e orienta a ação.

Para elaborar uma epistemologia da prática com o fim de orientar a formação do profissional prático reflexivo, Schön (2000) correlaciona a reflexão com diferentes momentos da atuação profissional e estabelece uma escala que parte do conhecimento tácito, ou saberes da experiência, até a prática reflexiva em sentido amplo. Os conceitos que designam as diferentes fases do ensino reflexivo são os seguintes:

a) Conhecer-na-ação: corresponde ao conhecimento implícito ou tácito, inerente ao talento artístico profissional, fruto da experiência ou de reflexões passadas, consolidado em esquemas semiautomáticos e rotinas. Por se tratar de uma competência que independe da capacidade de descrição ou explicitação de seus pressupostos por parte de quem o aciona, é fundamental, para o ensino reflexivo, que o conhecer-naação seja descrito. Quando isso acontece, o conhecer se converte em conhecimento-na-ação.

b) A reflexão na ação: o conhecer-na-ação permite ao prático acionar esquemas de ação que recobrem as situações previsíveis. Contudo, a prática educativa tem como uma de suas características a imprevisibilidade, demandando a necessidade de tomadas de decisões repentinas e, por isso, nem sempre fundadas em certezas advindas de algum procedimento de experimentação realizado fora do contexto situacional imediato. Em situações desse tipo, o profissional deve ser capaz de refletir na urgência da ação para tomar decisões. Assim como o conhecer-na-ação, a reflexão na ação é um processo que pode ser desenvolvido sem que haja a necessidade de descrição.

c) A reflexão sobre a ação e sobre a reflexão na ação podem ser consideradas como a análise que o profissional realiza a posteriori sobre as características e processos de sua própria ação. Consciente do caráter de reconstrução de sua própria lembrança e da possibilidade de 
que neste processo se produzam inevitáveis deformações subjetivas, o profissional deverá utilizar métodos, procedimentos e técnicas de contraste intersubjetivo ou dados registrados mais objetiva e mecanicamente sobre a própria realidade, a fim de minimizar os efeitos deformadores da atividade de reconstrução. (GÓMEZ, 1998)

A reflexão sobre a ação é um componente essencial do processo de aprendizagem permanente que constitui a formação profissional. Em tal processo, abrem-se para a consideração e questionamento, individual ou coletivo, não apenas as características da situação problemática sobre a qual atua o profissional prático, mas também sobre os procedimentos utilizados na fase de diagnóstico e definição do problema, na determinação dos objetivos, na escolha de métodos e na própria intervenção; além disso, a reflexão na ação permite a análise dos esquemas de pensamento, das teorias implícitas, das crenças e das formas de representar a realidade que o profissional utiliza nas situações problemáticas, incertas e conflitantes. Em suma, a reflexão sobre a ação supõe um conhecimento de terceira ordem, que analisa o conhecimento na ação e a reflexão na ação, correlacionando-os com a situação problemática e seu contexto.

\section{A perspectiva da reconstrução social}

Nessa perspectiva, agrupam-se aquelas posições que, mesmo com algumas diferenças, concebem o ensino como uma atividade crítica, uma prática social orientada por opções de caráter ético e político. O professor é considerado um profissional autônomo que reflete criticamente sobre a prática cotidiana para compreender tanto as características do processo de ensino-aprendizagem quanto do contexto em que o ensino ocorre. Desse processo de compreensão e reflexão, devem decorrer ações que visem à reconstrução ou à transformação social. Dentro dessa ampla perspectiva, é necessário distinguir dois enfoques: o da pedagogia crítica e o da pesquisa-ação e formação do professor para a compreensão.

No enfoque da pedagogia crítica (APPLE, 2008; APPLE \& BURRAS, 2008; APPLE, AU, GANDIN, 2011; FREIRE, 2011; PUCCI, 2007), a escola e a formação do professor são vistas como elementos 
cruciais no processo de realização de uma sociedade mais justa. Assim, a escola deve propor como objetivo prioritário o cultivo, em estudantes e docentes, da capacidade de pensar criticamente sobre a ordem social. O professor é considerado um intelectual transformador, com o claro compromisso político de promover a formação da consciência dos cidadãos na análise crítica da ordem social, para desmascarar as influências ocultas da ideologia dominante na prática cotidiana da aula, do currículo, na organização da vida na escola, na aula, nos sistemas de avaliação etc. Ao mesmo tempo, o professor é visto como um ativista político que deve intervir abertamente na análise e no debate dos assuntos públicos, além de provocar nos alunos o interesse e o compromisso crítico com os problemas coletivos. No Brasil, esse enfoque foi assimilado pela perspectiva acadêmica de formação docente, não chegando a constituir um programa efetivo de práticas formativas de profissionalização docente. Em outras palavras, apesar de muito presente no discurso acadêmico, os postulados da pedagogia crítica não se consubstanciaram em práticas efetivas que articulassem teorias relativas aos processos de ensino-aprendizagem e os conteúdos das disciplinas específicas na universidade ou na educação básica.

Pérez Gómez (1998) destaca três aspectos fundamentais enfatizados nas propostas de formação de professores orientadas por esse enfoque:

a) aquisição por parte do docente de um repertório cultural de base política e social. As disciplinas e temas voltados para as humanidades (língua, história, política, cultura etc.) são considerados os eixos centrais dos conteúdos de uma parte importante de seu currículo de formação;

b) o desenvolvimento de capacidades de reflexão crítica sobre a prática, para desmascarar as influências ocultas da ideologia dominante na prática cotidiana da aula, do currículo, na organização da vida na escola, na aula, nos sistemas de avaliação etc.;

c) o desenvolvimento de atitudes que requerem o compromisso político do professor como intelectual transformador na aula, na escola e no contexto social. 
O enfoque da investigação-ação ou da pesquisa-ação educacional tem como uma de suas principais características a recusa de um modelo de ensino orientado por objetivos previamente fixados, no qual o desenvolvimento do currículo é considerado uma mera tarefa instrumental. Como alternativa, propõe um modelo denominado processual, no qual os valores que regem a intencionalidade educativa devem ser erigidos e concretizados com base em princípios e procedimentos que orientem cada momento do processo de ensino. Nesse modelo, o desenvolvimento do currículo é construído pelo professor, que, por isso, deve aprofundar seus conhecimentos acerca dos valores educativos para transferir tais valores à prática de aula. Do ponto de vista metodológico, a investigação-ação aparece como o modo mais adequado de provocar, ao mesmo tempo, o desenvolvimento do currículo, a melhora da qualidade do ensino e o desenvolvimento profissional do professor.

Por se tratar de um modelo que prevê a redefinição constante do currículo escolar, é de se esperar que haja também reconfigurações constantes da estrutura curricular das instituições sociais legalmente designadas para a tarefa de formar professores. Esse fator pode suscitar questionamentos acerca das condições das universidades brasileiras para romper com sua estrutura organizacional marcadamente rígida, de modo a permitir a acomodação de propostas curriculares mais flexíveis.

Para além desses aspectos de cunho político-educacional, Zeichner (2008) chama a atenção para o fato de que, apesar do entusiasmo demonstrado por muitos que adotam a pesquisa-ação como método de formação de professores, não há evidências suficientes que comprovem os impactos positivos de tal metodologia na profissionalização docente.

No Brasil, a pesquisa-ação praticamente inexiste na formação inicial de professores, estando restrita aos cursos de pós-graduação stricto sensu. Desse modo, desenvolve-se tendo em vista objetivos voltados mais para fins de certificação acadêmica que de formação profissionalizante. 


\section{A profissionalização de professores de língua portuguesa: da legislação educacional à formação universitária}

Os modelos de formação profissional constituem referências importantes para as escolhas que se fazem no campo da política educacional, mas não se pode concluir que existe uma passagem direta da proposição para a ação, sem que haja um termo médio responsável pelas tarefas de ajuste normalmente necessárias quando se passa do campo teórico para o político. No Brasil, essa mediação fica a cargo do Ministério da Educação (MEC), que institui comissões compostas por especialistas e técnicos com o propósito de estabelecer bases legais para os diversos segmentos da educação, tendo em vista os objetivos da política educacional entendidos como adequados para fazer frente às demandas sociais. Com esse procedimento, espera-se de uma legislação educacional a consistência teórico-metodológica e política necessárias para erigir as referências formativas em âmbito nacional, sem que isso represente um hermetismo que anule a autonomia dos atores e instituições sociais envolvidos na complexa tarefa de educar, ou que impossibilite a emergência de elementos que possam conduzir a seu aperfeiçoamento.

Nesta seção, serão analisados os documentos legais que tratam da formação do professor de língua portuguesa, assim como sua relação com os modelos de formação docente em voga no discurso acadêmico brasileiro. Os documentos serão os seguintes: a Lei de Diretrizes e Bases da educação Nacional (LDBN 9.394/96), que estabelece as diretrizes e bases da educação nacional; o Parecer CNE/CES n 492, de 3 de abril de 2001, que aprova as Diretrizes Curriculares Nacionais do curso de Letras, e outros cursos; a Resolução CNE/CP 1, de 18 de fevereiro de 2002, que institui Diretrizes Curriculares Nacionais para a formação de professores da educação básica, em nível superior, curso de licenciatura, de graduação plena; a Resolução CNE/CP 2, de 19 de fevereiro de 2002, que institui a duração e a carga horária dos cursos de licenciatura, de graduação plena, de formação de professores da educação básica, em nível superior

O conjunto dos dispositivos que constituem as bases legais da formação do professor de língua portuguesa permite compreender a profissionalização docente como um processo complexo, ininterrupto, 
que deve se dar em consideração a três diferentes eixos: o da legislação educacional, que busca garantir o mínimo de unidade em termos de política nacional de educação; o da educação básica, determinado pela legislação e pela política educacional que definem os objetivos e fundamentos norteadores das práticas formativas da sociedade em nível básico comum; a formação profissional universitária, que também deve apresentar conformidade com a legislação e a política educacional, além de constituir uma das tarefas básicas da universidade (completam o conjunto de suas tarefas o desenvolvimento da pesquisa e a extensão universitária).

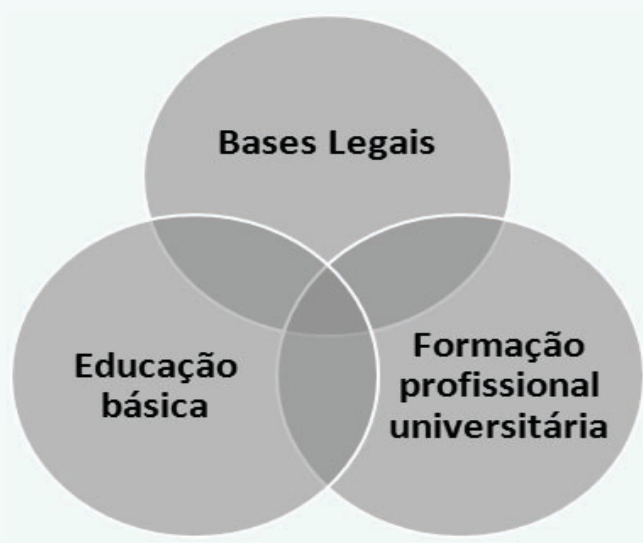

Figura 1 - Integração dos dispositivos institucionais de profissionalização docente.

ALDBN 9.394/96, dentre os vários aspectos sobre os quais dispõe, apresenta como um de seus principais destaques a obrigatoriedade do nível superior para os professores de todos os níveis da educação básica. Essa obrigatoriedade não constava da primeira versão oficial do texto, o que ocorreu após a publicação do Decreto $n^{\circ} 3.276$, de 6 de dezembro de 1999. Além disso, esse decreto estabelece, no Art. $5^{\circ}, \S 2^{\circ}$, que competirá às Diretrizes Curriculares Nacionais para a formação de professores assegurar, em consonância com as diretrizes curriculares definidas para a educação básica e tendo como referência os Parâmetros Curriculares Nacionais, a formação básica dos profissionais de educação. 
As Diretrizes Curriculares Nacionais, definidas no Parecer CNE/ $\mathrm{CES} \mathrm{n}^{\circ}$ 492, de 3 de abril de 2001, estabelecem que o egresso do curso de Letras deve apresentar as seguintes competências e habilidades (grifos meus):

domínio do uso da língua portuguesa ou de uma língua estrangeira, nas suas manifestações oral e escrita, em termos de recepção e produção de textos; reflexão analítica e crítica sobre a linguagem como fenômeno psicológico, educacional, social, histórico, cultural, político e ideológico;

visão crítica das perspectivas teóricas adotadas nas investigações linguísticas e literárias, que fundamentam sua formação profissional;

preparação profissional atualizada, de acordo com a dinâmica do mercado de trabalho;

percepção de diferentes contextos interculturais;

utilização dos recursos da informática;

domínio dos conteúdos básicos que são objeto dos processos de ensino e aprendizagem no ensino fundamental e médio;

dominio dos métodos e técnicas pedagógicas que permitam a transposição dos conhecimentos para os diferentes niveis de ensino.

Para que essas competências e habilidades sejam desenvolvidas, as Diretrizes fixam, de modo bastante geral, os conteúdos que devem ser contemplados na estrutura curricular dos cursos de Letras, reservando às instituições de nível superior a tarefa de estabelecer os contornos finais que garantirão a especificidade das disciplinas que comporão a matriz curricular, bem como sua organização. Os conteúdos são os seguintes (grifos meus):

De forma integrada aos conteúdos caracterizadores básicos do curso de Letras, devem estar os conteúdos caracterizadores de formação profissional em Letras. Estes devem ser entendidos como toda e qualquer atividade acadêmica que constitua o processo de aquisição de competências e habilidades necessárias ao exercício da profissão, e incluem os estudos linguísticos e literários, práticas profissionalizantes, estudos complementares, estágios, seminários, congressos, projetos de pesquisa, de extensão e de docência, cursos sequenciais, de acordo com as diferentes propostas dos colegiados das IES e cursadas pelos estudantes.

No caso das licenciaturas deverão ser incluídos os conteúdos definidos para a educação básica, as didáticas próprias de cada conteúdo e as pesquisas que as embasam. 


\begin{abstract}
O processo articulatório entre habilidades e competências no curso de Letras pressupõe o desenvolvimento de atividades de caráter prático durante o período de integralização do curso.
\end{abstract}

A aquisição ou construção de conhecimentos é condição necessária, mas não suficiente para o desenvolvimento de competências e habilidades. Para que ocorra uma relação produtiva entre esses elementos, é fundamental que a aprendizagem se dê de maneira situada. Ao estabelecer que os conteúdos curriculares da formação profissionalizante não devem ser apenas os de natureza estritamente acadêmica, mas incluir os de natureza social, tal como eles se manifestam na sociedade, assim como os conteúdos da educação básica, as Diretrizes reconhecem a especificidade de cada forma de conhecimento, sugerindo a ruptura com a concepção hierárquica dos saberes que ainda caracteriza as relações entre universidade e sociedade.

De modo análogo, a ênfase na relação entre conteúdos, competências e habilidades com a prática profissional rompe definitivamente com a perspectiva prática de enfoque tradicional, da qual deriva a concepção de professor como um artesão, e com a perspectiva acadêmica de enfoque enciclopédico, que concebe o professor como especialista em determinada área e que não distingue entre saber e saber ensinar. As Diretrizes, porém, não anulam a autonomia das instituições formadoras, como deve ser, por isso não estabelecem um modelo padrão de formação profissional. Isso dá margem para que os trechos que preconizam o uso de pesquisas no ensino possam ser assimilados pela perspectiva técnica de formação docente, que entende a prática profissional como um espaço de mera aplicação de teorias produzidas pela pesquisa acadêmica.

Na Resolução CNE/CP 1, de 18 de fevereiro de 2002, que Institui Diretrizes Curriculares Nacionais para a formação de professores da educação básica, em nível superior, curso de licenciatura, de graduação plena, a concepção do ensino como atividade complexa de caráter praxiológico fica ainda mais evidente. Nesse ponto, a legislação educacional mostra-se resolutamente refratária à concepção hierárquica que ainda orienta a estrutura curricular na universidade brasileira: em primeiro lugar a ciência básica, depois a ciência aplicada e, por fim, o espaço para o desenvolvimento das competências técnicas de caráter 
prático. No artigo da Resolução apresentado abaixo (grifos meus), ficam evidentes os pressupostos para um modelo de formação mais próximo da perspectiva prática de enfoque reflexivo.

Art. 12. Os cursos de formação de professores em nível superior terão a sua duração definida pelo Conselho Pleno, em parecer e resolução específica sobre sua carga horária.

$\S 1^{\circ} \mathrm{A}$ prática, na matriz curricular, não poderá ficar reduzida a um espaço isolado, que a restrinja ao estágio, desarticulado do restante do curso.

$\S 2^{\circ}$ A prática deverá estar presente desde o início do curso e permear toda a formação do professor.

$\S 3^{\circ}$ No interior das áreas ou das disciplinas que constituírem os componentes curriculares de formação, e não apenas nas disciplinas pedagógicas, todas terão a sua dimensão prática.

O Art. 13 da Resolução CNE/CP1 trata mais especificamente de aspectos metodológicos referentes ao estágio supervisionado. Nos documentos legais já referidos até o momento, não houve menção explícita aos métodos de formação prática, embora os pressupostos citados já permitam a rejeição de alguns modelos de formação profissional marcados, sobretudo, por uma hierarquização do conhecimento, com todas as consequências axiológicas que daí podem decorrer, e por uma visão dicotômica da relação teoria-prática. No artigo da Resolução abaixo, define-se como método de formação a resolução de situações-problema formuladas ou identificadas a partir de observações de práticas escolares e reflexões sobre elas. Com base nos dados coletados ou produzidos pelas reflexões, elabora-se o projeto de intervenção que será implementado para resolver problemas verificados no contexto situacional. Ganham destaque, dessa forma, as perspectivas de profissionalização que se aproximam do modelo prático reflexivo (SCHÖN, 2000), e o da pesquisa-ação educacional (MCKERNAN, 2009; PEREIRA e ZEICHNER, 2008). Tais modelos, no entanto, ainda não constituem referências significativas para a formação inicial de professores no Brasil.

Art. 13. Em tempo e espaço curricular específico, a coordenação da dimensão prática transcenderá o estágio e terá como finalidade promover a articulação das diferentes práticas, numa perspectiva interdisciplinar.

$\S 1^{\circ} \mathrm{A}$ prática será desenvolvida com ênfase nos procedimentos de observação e reflexão, visando à atuação em situações contextualizadas, com o registro dessas observações realizadas e a resolução de situações-problema. 
$\S 2^{\circ} \mathrm{A}$ presença da prática profissional na formação do professor, que não prescinde da observação e ação direta, poderá ser enriquecida com tecnologias da informação, incluídos o computador e o vídeo, narrativas orais e escritas de professores, produções de alunos, situações simuladoras e estudo de casos.

$\S 3^{\circ} \mathrm{O}$ estágio curricular supervisionado, definido por lei, a ser realizado em escola de educação básica, e respeitado o regime de colaboração entre os sistemas de ensino, deve ser desenvolvido a partir do início da segunda metade do curso e ser avaliado conjuntamente pela escola formadora e a escola campo de estágio.

A Resolução CNE/CP 2 estabelece a carga horária dos cursos de licenciatura plena, com destaque para a extensa carga horária de estágio supervisionado e de prática:

Art. $1^{\circ}$ A carga horária dos cursos de Formação de Professores da Educação Básica, em nível superior, em curso de licenciatura, de graduação plena, será efetivada mediante a integralização de, no mínimo, 2800 (duas mil e oitocentas) horas, nas quais a articulação teoria-prática garanta, nos termos dos seus projetos pedagógicos, as seguintes dimensões dos componentes comuns:

I - 400 (quatrocentas) horas de prática como componente curricular, vivenciadas ao longo do curso;

II - 400 (quatrocentas) horas de estágio curricular supervisionado a partir do início da segunda metade do curso;

III - 1800 (mil e oitocentas) horas de aulas para os conteúdos curriculares de natureza científico-cultural;

IV - 200 (duzentas) horas para outras formas de atividades acadêmicocientífico-culturais.

Chama a atenção a determinação de 400 horas de prática como componente curricular, que devem ser distribuídas ao longo do curso. Contudo, não fica claro se essa carga horária deve ser oferecida em forma de disciplinas específicas, ou se deve ser parte das disciplinas teóricas, como tempo para um trabalho prático ou aplicado. Qualquer uma das possibilidades poderá ser igualmente problemática ou aporética, já que pode esbarrar em dificuldades de operacionalização decorrentes da tradição universitária brasileira de formar professores por meio de especialistas. Se a carga horária de prática for oferecida através de disciplinas específicas, professores dessas disciplinas tra- 
dicionalmente teóricas poderão não dedicar espaço para um trabalho de natureza prática, não apenas em razão dos limites da carga horária, mas principalmente, por sua especialização puramente teórica. Logo, permanecerá a dicotomia entre teoria e prática, negada em toda a legislação. Por outro lado, se a carga horária for distribuída como parte das disciplinas teóricas, permanece a coerência projetada quanto à relação teoria-prática, mas também a falta de garantias de que um professor especialista conseguirá dar um enfoque prático aos conteúdos disciplinares eminentemente teóricos.

A ampliação da carga horária de estágio obrigatório para 400 horas, com início estabelecido para a segunda metade do curso, representa um avanço legal que ainda não se refletiu em boa parte da estrutura curricular das universidades brasileiras. É muito comum que o estágio supervisionado ocorra entre o penúltimo e o último semestres do curso. O Art. 10 da Lei $\mathrm{n}^{\circ} 11.788$, de 25 de setembro de 2008 , que dispõe sobre o estágio de estudantes, estabelece que a jornada de atividades de estágio deve ser definida de comum acordo entre a instituição de ensino, a parte concedente, ou seja, a instituição onde as atividades serão desenvolvidas e o aluno estagiário ou seu representante legal. Porém a diferença na forma como a escola e a universidade determinam o período letivo, esta por semestre, aquela por ano, pode ser um complicador das relações entre a escola e a universidade, considerando que o estágio se desenvolve por meio da parceria entre essas instituições. O principal problema que pode decorrer dessas diferentes maneiras de administração do tempo letivo é a impossibilidade de uma percepção totalizadora do funcionamento da educação básica, com impactos sobre os processos de diagnóstico, problematização, planejamento (parcial e global) e implementação de projetos de intervenção pedagógica, além de comprometer o processo de reflexão sobre as ações desenvolvidas. Consequentemente, o contato do estagiário com o contexto profissional se reduz a fragmentos situacionais, normalmente circunscritos a uma unidade letiva, e delimitados pelo recorte temporal do semestre letivo universitário.

Diante desses problemas, como distribuir a carga horária legalmente preconizada para o estágio obrigatório na estrutura curricular dos cursos de formação de professores? As 400 horas devem ser empregadas efetiva e integralmente no estágio, ou se referem ao estágio como 
disciplinas curriculares no interior das quais parte da carga horária é destinada ao estágio supervisionado? Se levarmos em consideração que a prática usual nas universidades brasileiras tem sido a realização do estágio em uma unidade letiva da escola, podemos concluir que a carga horária efetiva do estágio pode não chegar sequer à metade do que a lei determina. Para um aproveitamento adequado da carga horária estabelecida para o estágio, com reais possibilidades de uma formação prática capaz de fornecer ao estudante uma visão mais ampla da profissão, uma alternativa seria que os estagiários passassem um ano com, pelo menos, uma turma do $6^{\circ}$ ao $9^{\circ}$ ano do Ensino Fundamental e mais um ano com, pelo menos, uma das três séries do Ensino Médio.

\section{Considerações finais}

No Brasil, a simples concessão de um diploma de licenciado por parte de uma instituição de ensino superior devidamente regularizada transforma, ipso facto, seu portador, automaticamente, em um profissional legalmente habilitado para ensinar. Embora os cursos precisem da aprovação do MEC para funcionar, não há qualquer garantia de que a profissionalização conseguiu ir além da mera performatividade representada pela certificação, cujo símbolo máximo é o diploma, para se implementar, de fato, através da adoção de práticas e hábitos definidores de uma identidade profissional.

A legislação educacional, como se verificou, estabelece uma articulação necessária entre a política educacional unificadora, os objetivos do ensino na educação básica e aquilo que deve ser a formação universitária de nível superior. Em consequência dessa concepção integrada dos dispositivos institucionais de formação profissional do professor, os pressupostos teórico-metodológicas preconizados para a formação docente rompem não apenas com a relação dicotômica entre teoria e prática, mas também com a hierarquização dos conhecimentos, problemas ainda muito presentes na universidade brasileira.

$\mathrm{Na}$ teoria dos atos de fala, a performatividade só se concretiza quando as condições para que o dizer se transforme em ação são plenamente atendidas. Na conjuntura atual da formação universitária do professor de língua portuguesa, a condição mais relevante para a 
certificação que confere o status profissional tem sido a integralização curricular por parte do estudante.

Um caminho para solucionar esse problema poderia ser a realização de avaliações periódicas das licenciaturas pelo MEC, seguida das intervenções necessárias para ajustar a estrutura dos cursos ao que estabelecem as bases legais da educação e da formação profissional. Contudo, o fato de um instrumento como o Exame Nacional de Desempenho de Estudantes (Enade), que tem a finalidade de avaliar o rendimento dos concluintes dos cursos de graduação em relação aos conteúdos programáticos, habilidades e competências adquiridas em sua formação, abordar apenas aspectos teóricos relativos aos componentes curriculares dos cursos de licenciatura demonstra uma visão distorcida acerca da profissionalização do professor. Parte-se do pressuposto, comprovadamente infundado, de que a posse do conhecimento teórico, por sua própria natureza, é capaz de engendrar o componente praxiológico do ofício de professor. Fica evidente que a implementação da política educacional não se dá de maneira coerente com as normas e diretrizes que devem orientar as práticas formativas nas instituições legalmente designadas para fazê-lo. Nessas condições, a performatividade da licenciatura em Letras não é acompanhada de uma profissionalização efetiva. Permanece, portanto, a necessidade urgente de os dispositivos institucionais de formação de professores, destacadamente os organismos estatais e as universidades, alinharem discursos e práticas formativas de modo a torná-los coerentes com os objetivos estabelecidos na política educacional.

Recebido em: 10/08/2016

Aprovado em: 08/05/2018

E-mail: mabispo@uneb.br

\section{Referências}

Altet, M. 2000. Análise das práticas dos professores e das situações pedagógicas. Trad. Júlia Ferreira e José Cláudio. Porto: Porto Editora.

2001. As competências do professor profissional: entre conhecimentos, esquemas de ação e adaptação, saber analisar. In: Paquay, L.; Perrenoud, P.; Altet, M.; Charlier, E. (orgs.). Formando 
professores profissionais: quais estratégias? Quais competências? 2. ed. Trad. Fátima Murad; Eunice Gruman. Porto Alegre: Artmed.

Apple, M. W.; Buras, K. L. 2008. Currículo, poder e lutas educacionais: com a palavra, os subalternos. Trad. Ronaldo Cataldo Costa. Porto Alegre: Artmed.

Apple, M. W. 2008. Currículo e ideologia. Trad. Vinícius Figueira. 3. Ed. Porto Alegre: Artmed.

Apple, M. W.; Au, W.; Gaidin, L. A. 2011. Educação crítica. Trad. Vinícius Figueira. Porto Alegre: Artmed.

BRASIL. 1996. Lei de Diretrizes e Bases da educação Nacional n 9.394 , de 20 de dezembro de 1996. Estabelece as diretrizes e bases da educação nacional.

. 1999. Decreto $n^{0} 3.276$, de 6 de dezembro de 1999. Dispõe sobre a formação em nível superior de professores para atuar na educação básica, e dá outras providências.

. 2001. Conselho Federal de Educação. Parecer CNE/CES nº 492, de 3 de abril de 2001. Aprova as Diretrizes Curriculares Nacionais do curso de Letras, e outros cursos.

. 2002. Conselho Federal de Educação. Resolução CNE/CP 1, de 18 de fevereiro de 2002. Institui Diretrizes Curriculares Nacionais para a formação de professores da educação básica, em nível superior, curso de licenciatura, de graduação plena.

2002. Conselho Federal de Educação. Resolução CNE/CP 2, de 19 de fevereiro de 2002. Institui a duração e a carga horária dos cursos de licenciatura, de graduação plena, de formação de professores da educação básica, em nível superior. 2008. Lei $\mathrm{n}^{\circ} 11.788$, de 25 de setembro de 2008. Dispõe sobre o estágio de estudantes.

Dewey, J. 1997. Experience and education. New York: Touchstone.

Freire, P. 2011. Educação e mudança. Trad. Lilian Lopes Martin. 34. Ed. Rev. e atual. São Paulo: Paz e Terra.

Hartman, H. J. 2015. Como ser um professor em todas as áreas do conhecimento. Trad. Alexandre Salvaterra. Porto Alegre: AMGH Editora.

McKernan, J. 2009. Currículo e imaginação: teoria do processo, pedagogia e pesquisa-ação. Trad. Gisele Klein. Porto Alegre: Artmed.

Paquay, L.; Perrenoud, P.; Altet, M. Charlier, E. (orgs.). 2001. Formando professores profissionais: quais estratégias? Quais competências? 2. ed. Trad. Fátima Murad; Eunice Gruman. Porto Alegre: Artmed.

Paquay, L.; Van Nieuwenhoven, C.; Wouters, P. (org.). 2012. A avaliação como ferramenta de desenvolvimento profissional de educadores. Trad. Fátima Murad. Porto Alegre: Penso. 
Pereira, J. E. D.; Zeichner, K. M. (orgs.). 2008. A pesquisa na formação e no trabalho docente. Trad. Erick Ramalho. Belo Horizonte: Autêntica. p. 67-93.

Pérez Gómez, A. I. 1998. A função e formação do professor/a no ensino para a compreensão: diferentes perspectivas. In: SACRISTÁN, J. G.; Gómez, A. I. P. Compreender e transformar o ensino. 4. ed. Trad.: Ernani F. da Fonseca Rosa. Porto Alegre: Artmed. p. 353-380.

Perrenoud, P. 2002. A prática reflexiva no ofício de professor: profissionalização e razão pedagógica. Trad. Cláudia Schilling. Porto Alegre: Artmed.

Plaisance, E.; Vergnaud, G. 2003. As ciências da educação. Trad. Nadyr de Salles Penteado; Odila Aparecida de Queiroz. São Paulo: Edições Loyola.

Romanelli, O. O. 2003. História da educação no Brasil. 28. Ed. Petrópolis: Editora Vozes.

Pucci, B. (org.). 2007. Teoria crítica e educação: a questão da formação cultural na escola de Frankfurt. 4. Ed. Petrópolis, RJ: Vozes; São Carlos, SP: EDUFSCAR.

SACRISTÁn, J. G.; Gómez, A. I. P. 1998. Compreender e transformar $o$ ensino. 4. ed. Trad. Ernani F. da Fonseca Rosa. Porto Alegre: Artmed.

Schön, D. A. 2000. Educando o Profissional Reflexivo: um novo design para o ensino e a aprendizagem. Trad. Roberto Cataldo Costa. Porto Alegre: Artmed.

TARDIF, M. 2011. Saberes docentes e formação profissional. 12. ed. Trad.: Francisco Pereira. Petrópolis, RJ: Vozes.

Weinstein, C. S.; Novodvorsky, I. 2015. Gestão da sala de aula: lições da pesquisa e da prática para trabalhar com adolescentes. 4. Ed. Trad. Luís Fernando Marques Dorvillé. Porto Alegre: AMGH.

ZEICHNER, K. M. 2008. A pesquisa-ação e a formação docente voltada para a justiça social: um estudo de caso dos Estados Unidos. In: PereirA, J. E. D.; ZEICHNER, K. M. (orgs.). 2008. A pesquisa na formação e no trabalho docente. Trad. Erick Ramalho. Belo Horizonte: Autêntica. p. 67-93. 